CASO CLÍNICO

\title{
Cáncer medular de tiroides metastásico a la cavidad oral: caso clínico
}

\section{Luis Cruz-Benítez ${ }^{1, *}$, Angélica Julián-Castrejón ${ }^{2}$ y Juan de Dios Pérez-Reyna ${ }^{3}$}

${ }^{1}$ Servicio de Cirugía Oncológica; ${ }^{2}$ Servicio de Cirugía Maxilofacial, Hospital Regional de Alta Especialidad de Ixtapaluca (HRAEI), SS, Ixtapaluca, México; ${ }^{3}$ Hospital General Dr. Darío Fernández Fierro, Instituto de Seguridad y Servicios Sociales de los Trabajadores del Estado (ISSSTE), Ciudad de México, México

Recibido el 11 de noviembre de 2016; aceptado el 25 de febrero de 2017

Disponible en Internet el 14 de julio de 2017

\section{PALABRAS CLAVE \\ Cáncer medular; Cáncer papilar; Tiroidectomía total; Disección radical de cuello; Metástasis}

\begin{abstract}
Resumen El cáncer medular de tiroides (CMT) corresponde a una neoplasia de las células C, las cuales tienen por función regular el metabolismo del calcio. Tiene una baja frecuencia (alcanza el $5 \%$ de todos los cánceres tiroideos) y suele presentarse en forma esporádica $(84 \%)$ o hereditaria (16\%), esta última en el contexto de un carcinoma medular de tiroides familiar (CMTF) o de una neoplasia endocrina múltiple tipo 2 (NEM 2), la cual se asocia a distintas mutaciones del protooncogén REarranged during Transfection 4 (RET-4). Tiene la característica de secretar calcitonina (CT), un marcador útil para el estadiaje, la enfermedad residual y el seguimiento de los pacientes a largo plazo. Es una neoplasia relativamente agresiva, ya que, a pesar de su lenta progresión, en el momento del diagnóstico un 60-80\% tienen metástasis lin fáticas, lo que dificulta una terapia totalmente curativa, ya que se ha visto que después de là primera cirugía más del $50 \%$ de los pacientes mantienen niveles de CT elevados. Los pacientes con la forma hereditaria tienden a ser más jóvenes y a presentar una enfermedad de curso más agresivo, con un cáncer que suele ser multifocal y bilateral. La terapia de primera línea es la cirugía. (creativecommons.org/licenses/by-nc-nd/4.0/).
\end{abstract}

*E-mail para correspondencia: crubeluis@gmail.com, crubeluis@yahoo.com.mx (L. Cruz-Benítez) 


\section{INTRODUCCIÓN}

Una gran variedad de lesiones, ya sean malignas o benignas, podrían causar nódulos tiroideos; por lo tanto, todo paciente con esta condición deberá ser investigado en relación con sus antecedentes familiares de enfermedad tiroidea benigna o maligna (CMT, NEM 2, tumores papilares tiroideos familiares, poliposis coli, enfermedad de Cowden, síndrome de Gardner y complejo de Carney) ${ }^{1}$. Un nódulo tiroideo se define como la presencia de una o más lesiones focales, ya sean palpables o visibles a través de estudios de imagen, que difieren de la estructura del parénquima tiroideo'.

El CMT fue reconocido en el año 1959 por Hazard, et al., quienes describieron una variedad de cáncer tiroideo sólido no folicular, con un estroma rico en sustancia amiloidea y alta incidencia de metástasis ganglionares. En 1967 Williams y Brewer describieron que el CMT se origina en las células parafoliculares $(C)$ de la glándula tiroides. Un año después, Neher comprobó que este tipo de tumor secreta tirocalcitonina ${ }^{3,4}$.

El CMT corresponde a una neoplasia de las células $C$, que producen $\mathrm{CT}$, las cuales tienen por función regular el metabolismo del calcio. Tiene una baja frecuencia, pues alcanza el 4-5\% de todos los cánceres tiroideos ${ }^{2,5,6}$. Suele presentarse en forma esporádica (84\%)5 o hereditaria (16\%), esta última en el contexto de un CMTF o de una NEM 2, la cual se asocia a distintas mutaciones del protooncogén RET-46. Algunas veces este cáncer se puede propagar a los ganglios linfáticos, los pulmones o el hígado, incluso antes de que se detecte un nódulo tiroideo. Este tipo de cáncer de tiroides es más difícil de descubrir y tratar ${ }^{2}$.

Tiene la característica de secretar CT, un marcador útil para el estadiaje, la enfermedad residual y el seguimiento de los pacientes a largo plazo. Es una neoplasia relativamente agresiva, ya que, a pesar de su lenta progresión, en el momento del diagnóstico el $60-80 \%$ tienen metástasis linfáticas $^{8-12}$, lo que dificulta una terapia totalmente curativa, ya que se ha visto que después de la primera cirugía más del $50 \%$ de los pacientes mantienen niveles de CT elevados ${ }^{2}$. Los pacientes con la forma hereditaria tienden a ser más jóvenes y a presentar una enfermedad de curso más agresivo, con un cáncer que suele ser multifocal y bilateral ${ }^{2}$.

Hay dos tipos de CMT:

- El CMT esporádico representa aproximadamente 8 de cada 10 casos de CMT, y no es hereditario. Este cáncer ocurre principalmente en adultos de edad avanzada y afecta únicamente a un lóbulo tiroideo ${ }^{2}$.

- El CMTF es hereditario y el 20-25\% pueden surgir en cada generación de una familia. A menudo, estos cánceres se desarrollan durante la niñez o en la adultez temprana y se pueden propagar temprano. Los pacientes usualmente tienen cáncer en varias áreas de ambos lóbulos. El CMTF a menudo se asocia con un riesgo aumentado de sufrir otros tipos de tumores ${ }^{2}$. El CMTF puede estar asociado a hipercalcemia y tumores adrenales (feocromocitomas) ${ }^{13}$.

El CMTF forma parte de la NEM 2, cuya clasificación es la siguiente ${ }^{14,15}$ :

- Neoplasia endocrina múltiple tipo 2A (síndrome de Sipple): CMT, feocromocitoma e hiperparatiroidismo primario.

- Neoplasia endocrina múltiple tipo 2B: CMT, feocromocitoma, ganglioneuromatosis intestinal y en las mucosas, y hábito marfanoide ${ }^{14,15}$.
- Carcinoma medular de tiroides familiar: familias con más de 10 portadores de la mutación o bien familias con múltiples portadores o miembros afectados mayores de 50 años, después de practicar una historia clínica detallada para descartar otros tumores endocrinos. También, según la clasificación de Eng, et al. ${ }^{16}$, son familias con cuatro o más miembros afectados.

- Neoplasia endocrina múltiple tipo 2A con liquen amiloideo.

- Neoplasia endocrina múltiple tipo 2A o CMTF con en-y fermedad de Hirschsprung ${ }^{4,15,16}$.

\section{CUADRO CLÍNICO}

Suele presentarse como un nódulo tiroideo palpable. Puede acompañarse de síntomas sistémicos como diarreas y flash, más frecuentes en pacientes con grandes tumores. Las metástasis en los ganglios paratraqueales y cervicales laterales se presentan en forma precoz, en el $20-30 \%$ de tumores < 1 $\mathrm{cm}$, en el $50 \%$ de tumores de entre 1 y $4 \mathrm{~cm}$ y hasta en el $90 \%$ de tumores $>4 \mathrm{~cm}$ o T4. Los tumores con rápido crecimiento pueden manifestarse con síntomas por invasión local (disfonía, disfagia y disnea) en un $15 \%^{3}$.

El 5-10\% de los casos se presentan con metástasis a distancia al pulmón, el hígado, el hueso y, en forma menos fre cuente, la piel y el sistema nervioso central. Las metástasis a distancia son la principal causa de muerte y en la mitad de los casos ya están presentes al diagnóstico. Las metástasis pulmonares son macro o micronodulares y, en general, son difusas y bilaterales. Las óseas son lesiones osteolíticas u osteoblásticas, con incremento de la captación en el centello. grama. Las de hígado presentan una imagen hiperecogénica en la ecografía, y si son pequeñas, pueden confundirse con hemangiomas hepáticos ${ }^{3}$.

\section{DIAGNÓSTICO}

Hay que realizar pruebas genéticas a todas las personas diagnosticadas con CMT. La prueba genética se considera el estándar de cuidado, no una prueba de investigación. Si se ha determinado que el paciente padece CMT, se debe estudiar a los miembros de su familia inmediata para deter-o minar si existen factores genéticos que puedan predecir el desarrollo del CMT. Las pruebas se enfocan en el protoonco-o gén RET. En los individuos que presentan estas alteraciones genéticas, incluyendo niños e infantes, la extirpación quirúrgica de la glándula tiroides antes de que el cáncer tenga la oportunidad de desarrollarse tiene una alta probabilidad de ser una cura preventiva. Casi el $100 \%$ de los pacientes que presentan la mutación (una secuencia anormal en el protooncogén RET) desarrollarán eventualmente CMT. Esta mutación específica sirve para determinar si hay que extirpar o no la glándula tiroides ${ }^{13}$.

El protooncogén RET se encuentra en el cromosoma 10q11.2, formado por 21 exones. Codifica para un receptor de membrana con actividad de tirosin-cinasa. Se expresa en células derivadas de la cresta neural: células $C$, paratiroides, células cromafines de la médula adrenal, plexo autonómico entérico y tracto urogenital ${ }^{3}$.

Los CMT normalmente producen CT y antígeno carcinoembrionario $(\mathrm{ACE})$, que se pueden medir con pruebas de 
sangre $^{12}$. La CT es un péptido de 32 aminoácidos, codificado en el cromosoma 11. Es el principal marcador tumoral en el CMT con alta sensibilidad y especificidad. Se usa en el screening inicial y para el seguimiento postoperatorio ${ }^{3}$.

También aumenta en los neonatos, durante el embarazo y la lactancia, en la insuficiencia renal, en la tiroiditis, en los tumores foliculares, en la hiperplasia de células $C$ y en los tumores endocrinos del páncreas y el tracto respiratorio ${ }^{3}$. El ACE, que es útil para el seguimiento, tiene una menor sensibilidad y especificidad que la $\mathrm{CT}^{3}$.

El CMT no tiene la capacidad de absorber yodo. Debido a esto, no se debe utilizar yodo radioactivo en el tratamiento del $\mathrm{CMT}^{13}$. Varios estudios han demostrado que el CMT presenta compromiso locorregional en un alto porcentaje al diagnóstico ${ }^{8,10}$, lo que constituye uno de los principales problemas que enfrentan estos pacientes, permitiendo el desarrollo de enfermedad persistente y/o recidiva ${ }^{2}$.

\section{TRATAMIENTO}

La terapia de primera línea es la cirugía.

\section{Tratamiento primario}

Consiste en una tiroidectomía total y la resección de todo el tejido neoplásico presente en el cuello. Se dan los siguientes casos $^{3}$ :

- Pacientes sin evidencia clínica/imágenes de metástasis ganglionares: resección profiláctica del compartimento central (nivel $\mathrm{VI})^{3}$.

- Sospecha de metástasis limitadas al compartimento central: resección de nivel VI (algunos avalan la disección lateral profiláctica ${ }^{3}$ ).

- Compromiso central y lateral por imágenes prequirúrgicas: resección del compartimento central y lateral (niveles IIA, III, IV y V) ${ }^{3}$.

- Ante metástasis a distancia o enfermedad localmente avanzada, se puede realizar una cirugía menos agresiva para preservar la deglución, el habla y la función paratiroidea $^{3}$.

\section{Tratamiento del cáncer medular tiroideo hereditario}

- En presencia de feocromocitoma: primero, cirugía adrenal. Hay que identificar las cuatro paratiroides durante la cirugía (tinción con azul de metileno): si tienen un aspecto normal, pueden dejarse o implantarse en un músculo ${ }^{3}$.

- En presencia de hiperparatiroidismo:

- Si hay evidencia de adenoma, se reseca y se trasplantan las restantes.

- Si se observa hiperplasia difusa se realiza la resección de $3 \frac{1}{2}$ glándulas y el autotransplante del remanente al antebrazo no dominante ${ }^{3}$.

Su pronóstico a largo plazo no es tan positivo como el de los cánceres tiroideos bien diferenciados. Sin embargo, en años recientes, se han llevado a cabo ensayos clínicos que han probado nuevos fármacos promisorios para el tratamiento del CMT progresivo. Uno de estos fármacos es el vandetanib (Caprelsa), el cual ha sido aprobado por la Food and Drug Administration (FDA) de EE.UU. para pacientes seleccionados con $\mathrm{CMT}^{12}$.

\section{METÁSTASIS DE CARCINOMA MEDULAR DE TIROIDES EN LA CAVIDAD ORAL}

El cáncer bucal representa aproximadamente el $8 \%$ de to dos los tumores malignos, y el $99 \%$ de éstos corresponden a carcinomas; los más comunes son los de lengua (27\%), encia (17\%), glándulas salivales (16\%) y piso de la boca (13\%); el 27 restante corresponden a otros sitios. El sexo masculino es el más afectado, con una relación $2: 1$. Se presentan casi siempre en pacientes mayores de 40 años. Las metástasis que afectan a la cavidad bucal representan el $1 \%$ de las lesiones tumorales malignas; y en el $30 \%$ de casos son la primera manifestación de un tumor maligno que se ha mantenido oculto y asintomático. Clínicamente aparentan ser lesiones benignas o reactivas de la cavidad bucal ${ }^{16-19}$. El componente óseo es el que más se afecta en relación con las partes blandas, sobre todo el maxilar inferior a nivel de premolares y molares, probablemente por un ser un área muy vascularizada y por contener tejido hematopoyético con mayor actividad $^{20-21}$.

Es importante mencionar que cerca de la mitad de los cánceres medulares tienen metástasis ganglionares al diag nóstico y que el $17.5 \%$ tienen también metástasis distantes ${ }^{2}$. Las metástasis a la cavidad bucal deben tratarse localmente para evitar una lesión ulcerada y dolorosa, facilitar la mas:ticación y evitar una deformación local. El tratamiento será individual en cada caso en particular, teniendo presente que si se retiran estas lesiones únicamente con tratamiento quirúrgico, la posibilidad de recidiva es alta.

\section{PRESENTACIÓN DEL CASO}

Paciente femenina de 48 años de edad, ocupada en labores de intendencia. Niega enfermedades crónico-degenerativas, alérgicos, traumáticos, quirúrgicos. Es valorada en el

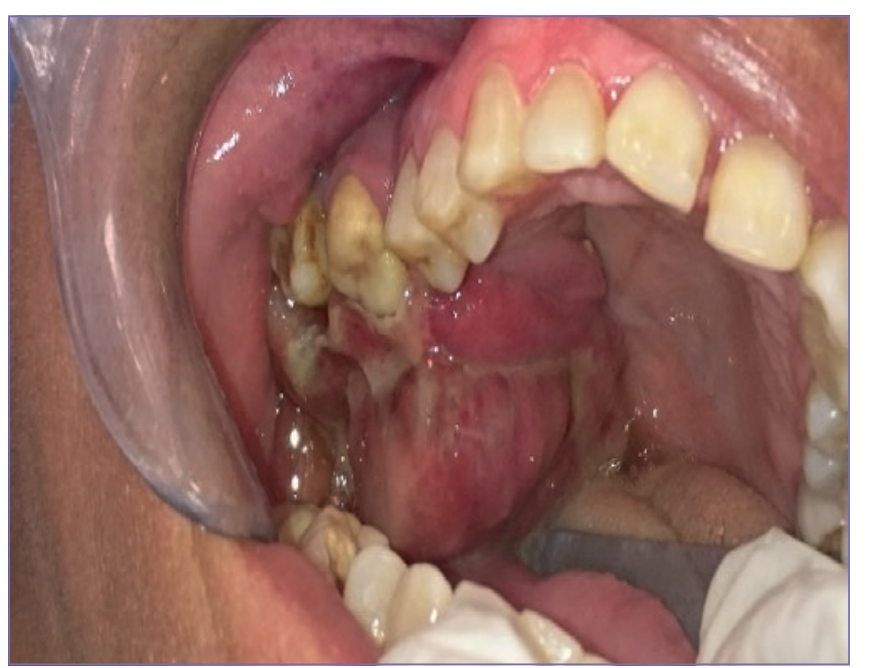

Figura 1. Se observa en la cavidad oral un tumor maxilar superior derecho, de aspecto pediculado, de $3 \times 4 \mathrm{~cm}$ de diámetro. 


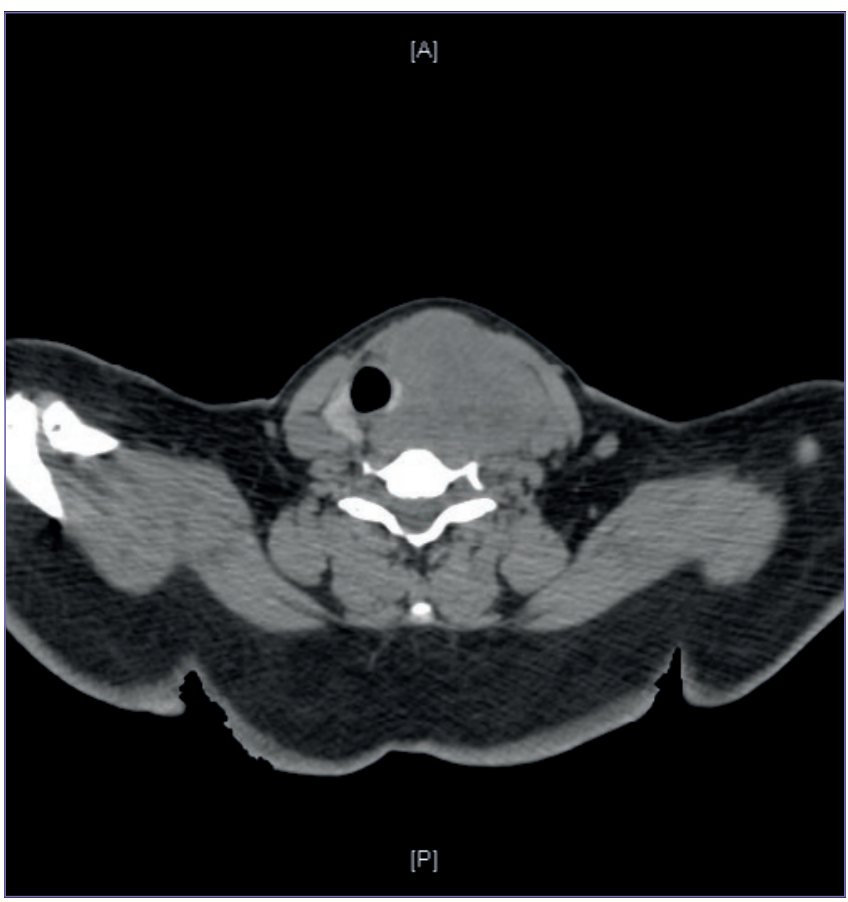

Figura 2. Tomografía computarizada de cuello, corte axial: nódulo heterogéneo dependiente del lóbulo izquierdo, que mide $8.6 \times 6.1 \times 6.1$ $\mathrm{cm}$ en sus ejes mayores.

Servicio de Oncología y Cirugía Maxilofacial, a donde acude por presentar un aumento de volumen en la región bucal, sangrante, de tres meses de evolución, que le ocasiona molestias y sangrado durante la masticación, así como un aumento de volumen en el cuello de predominio izquierdo, de un año de evolución, con crecimiento progresivo, disnea y dolor ocasional, disfagia a sólidos y adinamia. Durante la exploración física se detecta en la región de la cavidad oral una lesión friable, sangrante a la palpación y de apariencia granulomatosa, de $6 \times 5 \mathrm{~cm}$ de diámetro aproximadamente en la región del trígono retromolar que involucra la movilidad del primer y segundo molares superiores derechos (Fig. 1), ulcerada y friable; en el cuello presenta múltiples adenopatías, de $1.5 \mathrm{~cm}$, niveles II A y IIIA, en el cuello del lado izquierdo; un tumor de cuello bilateral, de predominio izquierdo, de $15 \times 4 \mathrm{~cm}$ de diámetro, de consistencia dura, poco móvil del lado izquierdo, y un tumor del lado derecho, de $6 \times 4 \mathrm{~cm}$ de diámetro, de consistencia dura, poco móvil. El día 28 de agosto de 2015 se realiza una biopsia del tumor maxilar superior derecho, que reporta que se trata de un cáncer epidermoide en la región maxilar.

Se procede a iniciar el protocolo de preparación quirúrgica para la resección del tumor de la cavidad oral, así como una tumorectomía de cuello. Se solicita una telerradiografía de tórax, pero no se observan lesiones de aspecto metastásico. También se realiza una angiotomografía computarizada del macizo facial y el cuello, donde se reporta una lesión hipodensa en fase simple, a nivel del maxilar superior, en el lado derecho, que condiciona erosión ósea y de la base de las apófisis pterigoides; mide $4 \times 3.7 \times 3.2 \mathrm{~cm}$ aproximadamente en sus ejes mayores y presenta reforzamiento tras la administración del medio de contraste intravenoso, aumento en las dimensiones de la glándula tiroides por un nódulo heterogéneo dependiente del lóbulo izquierdo, que refuerza

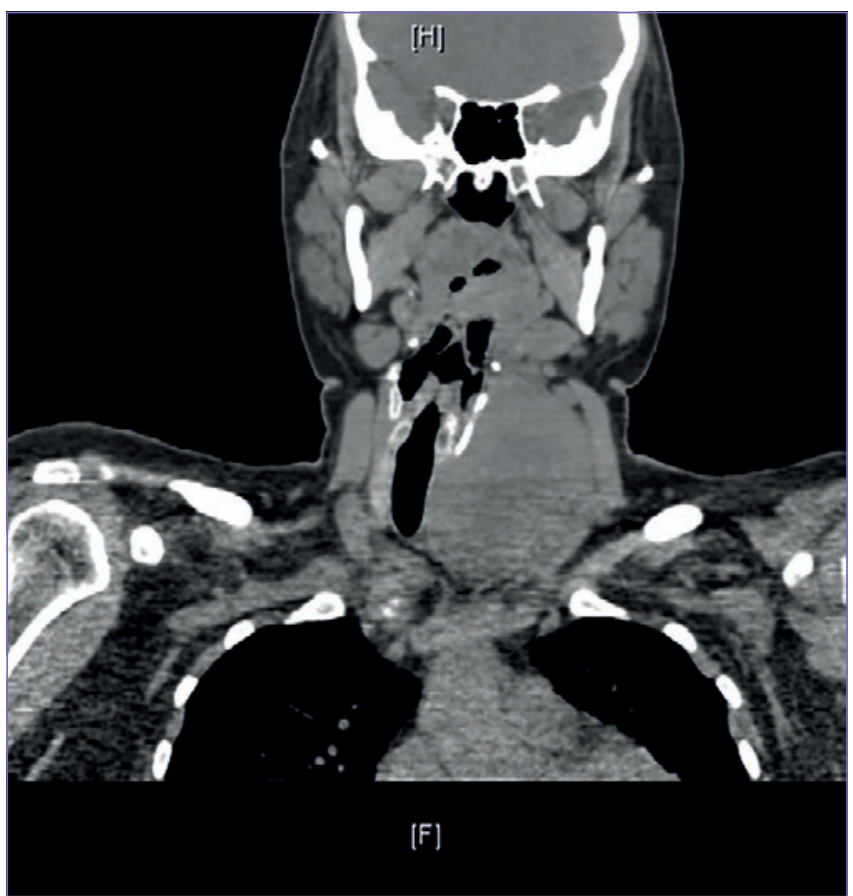

Figura 3. Tomografía computarizada de cuello, corte coronal: tumor que refuerza en la periferia y condiciona el desplazamiento de la vía aérea hacia la derecha.

en la periferia, mide $8.6 \times 6.1 \times 6.1 \mathrm{~cm}$ en sus ejes mayores y condiciona un desplazamiento de la vía aérea hacia la derecha (Figs. 2 y 3). Perfil tiroideo: TSH: $2.71 \mathrm{mUI} / \mathrm{l}, \mathrm{T} 3$ total (triyodotironina): $1.59 \mathrm{ng} / \mathrm{ml}$, T3 libre: $3.38 \mathrm{pg} / \mathrm{ml}$, T4 total (tiroxina): $6.56 \mu \mathrm{g} / \mathrm{dl}$, T4 libre: $0.78 \mathrm{ng} / \mathrm{dl}$, hormona paratiroidea: $25.2 \mathrm{pg} / \mathrm{ml}$.

La paciente se somete a una biopsia excisional con el diente involucrado de la región maxilar derecha (Fig. 4) y una hemitiroidectomía izquierda con los siguientes hallazgos: tumor tiroideo izquierdo, muy vascularizado, con infiltración a los tejidos adyacentes, de $10 \times 6 \times 5 \mathrm{~cm}$ de diámetro (Fig. 5) y de consistencia blanda, y tiroides derecha normal. Se reseca la hemitiroides izquierda y se envía a estudio transoperatorio con reporte de tumor folicular versus adenoma tiroideo. Se resecan la hemitiroides derecha y la glándula paratiroides inferior izquierda. Se respetan los nervios laríngeos recurrentes (Fig. 6). Se da por terminado el acto quirúrgico, sin incidentes ni complicaciones, con un sangrado de $300 \mathrm{ml}$. La paciente cursa con una adecuada evolución clínica postoperatoria, con una ligera disfonía, tolerancia a la vía oral y drenaje del cuello con gasto serohemático escaso, por lo que se decide el egreso a su domicilio.

Posteriormente se emite el diagnóstico anatomopatológico definitivo con el siguiente reporte: lóbulo tiroideo iz quierdo con CMT, de $6.7 \times 5.2 \times 4.9 \mathrm{~cm}$ de tamaño, con bordes quirúrgicos negativos para células neoplásicas y datos de invasión vascular y perineural, sin extensión extratiroidea; lóbulo tiroideo derecho sin datos de carcinoma medular, con datos de microcarcinoma papilar, clásico, de $0.5 \mathrm{~cm}$, con bordes quirúrgicos negativos, sin invasión vascular, perineural o extratiroidea. La biopsia de la lesión maxilar derecha reporta un carcinoma medular metastásico.

Ante este diagnóstico, se procede a realizar la disección radical de cuello bilateral modificada tipo III. Se observan 


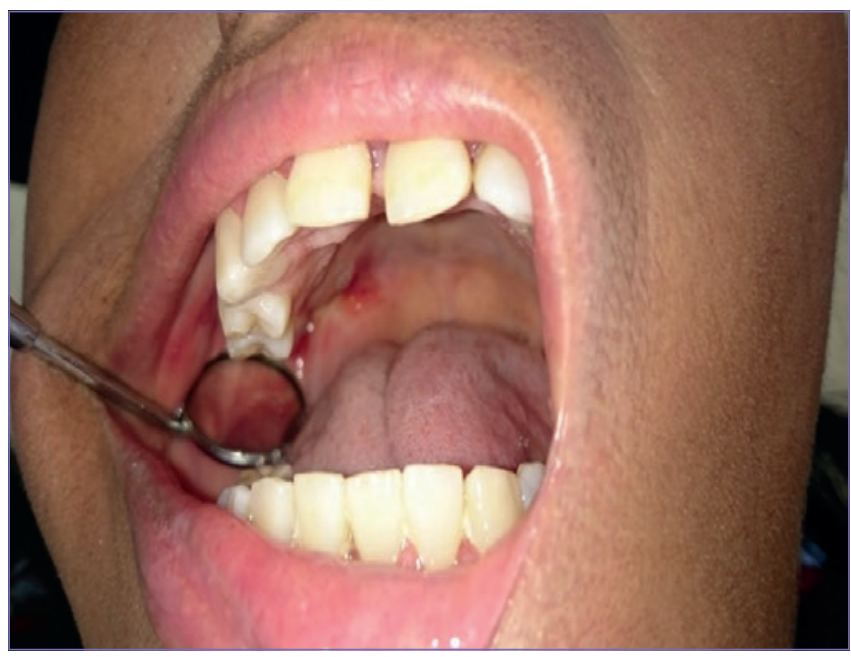

Figura 4. En esta imagen se observa la cavidad oral posterior a la biopsia excisional de la lesión.

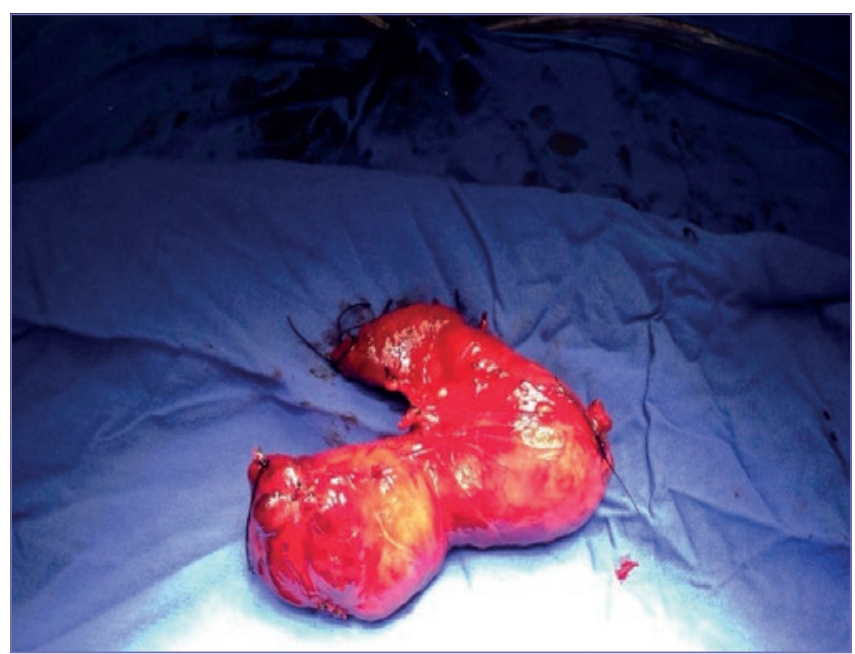

Figura 5. Tumor tiroideo izquierdo, muy vascularizado, con infiltración a tejidos adyacentes, de $10 \times 6 \times 5 \mathrm{~cm}$ de diámetro.

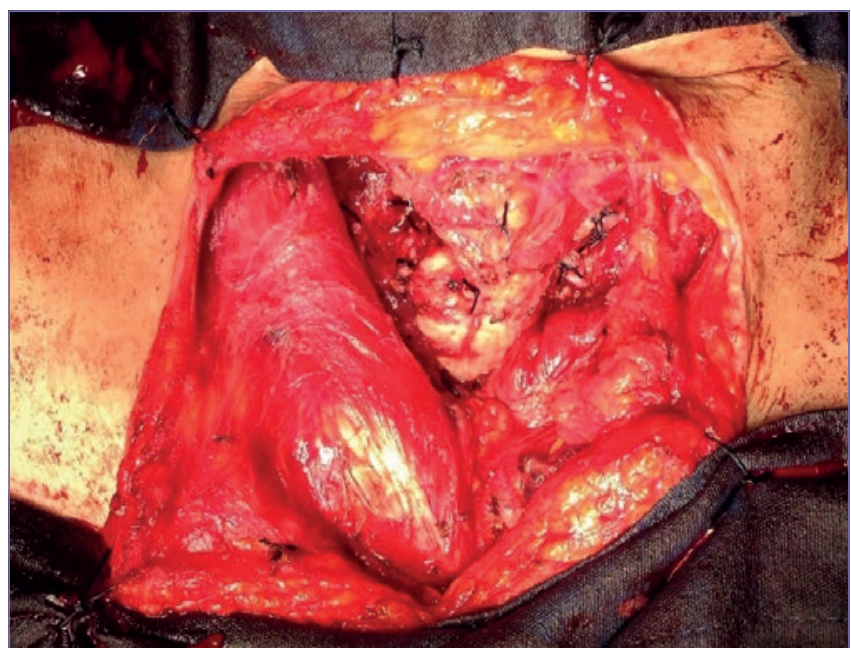

Figura 6. Lecho tiroideo donde se observa la completa resección de la glándula tiroidea al resecarse también la hemitiroides derecha y la glándula paratiroides inferior izquierda, respetando los nervios laríngeos recurrentes. como hallazgos adenopatías bilaterales de $1 \mathrm{~cm}$ en ambos lados del cuello de nivel III. El reporte de histopatología refiere: disección ganglionar de cuello del lado derecho con 15 ganglios linfáticos sin evidencia de malignidad; disección ganglionar de cuello del lado izquierdo con nueve ganglios linfáticos, libres de malignidad, inactivos. Se identifica una glándula paratiroides con hiperplasia, libre de malignidad. Con estos resultados se estadifica como un CMT izquierdo, estadio clínico IV por T3 N0 M1 y cáncer micropapilar de tiroides derecha, EC I por T1a NO MO.

La paciente es valorada por radiooncología y se decide administrar radioterapia adyuvante conformal al cuello con el área del lecho quirúrgico y la cavidad oral, así como cadenas yugulares a dosis de $68 \mathrm{~Gy}$ al primario en 34 fracciones, terminando sin alteraciones.

Actualmente la paciente se encuentra en tratamiento con levotiroxina $100 \mu \mathrm{g}$ /día, con una leve disfonía, y tolera la vía oral; en la exploración física no se observan datos de recurrencia clínica tumoral, ni radiológica, a los tres meses del término del tratamiento.

\section{DISCUSIÓN}

El CMT es un cáncer de baja frecuencia y curso agresivo lo calmente, con un pronóstico intermedio entre los cánceres diferenciados y el anaplásico. Sin embargo, se ha visto que estos pacientes logran tasas de sobrevida elevadas a largo plazo, de entre el 50 y el 85\%, a 15 años de seguimiento. Así, podemos vislumbrar que es un gran desafío tratar adecuadamente a los pacientes con CMT hereditario, principalmente dentro del contexto de una NEM.

Como pautas de tratamiento existen las siguientes modalidades: la cirugía se considera el único tratamiento curativo. Cuando se tienen pacientes con enfermedad residuat o recurrente o con metástasis a distancia, la radioterapia externa puede indicarse en casos seleccionados (adyuvante o paliativa). La quimioterapia sistémica tiene una eficacia muy limitada, con respuesta parcial sólo en el $10-20 \%$ de los casos (dacarbazina, 5-fluorouracilo y doxorubicina). La pre-o sencia de mutaciones activadoras del gen RET hace que los futuros tratamientos dirigidos a su inhibición sean una alternativa, y, por ende, una posibilidad de mejorar la sobrevida libre de progresión de estos pacientes ${ }^{13}$.

La duplicación en el tiempo (doubling time [DT]) de la CT y el ACE se correlaciona significativamente con la progresión de la enfermedad y es un factor predictivo importante de supervivencia. En aquellos pacientes con CT detectable basal y sin evidencia de enfermedad, se determinan la CT y el ACE basales y cada seis meses para estimar la DT. Derivado de ello, se desglosa lo siguiente ${ }^{13}$ :

- Cuando la DT de la CT es < 6 meses, la tasa de super vivencia a 5 y 10 años es del 25 y el $8 \%$, respectivamente ${ }^{13}$.

- Si la DT de la CT es de entre 6 y 24 meses, la supervivencia a 5 y 10 años es del 92 y el $37 \%$, en ese orden ${ }^{13}$.

- En pacientes con una DT de la CT > 2 años, la supervivencia a 5 años es del $100 \%{ }^{13}$.

Con respecto al pronóstico, el $90 \%$ de los pacientes con CMT hereditario con detección precoz por screening permanecen libres de enfermedad. Según la clasificación de TNM, la tasa de supervivencia a 10 años para los estadios I, II, 
III y IV es del 100, el 93, el 71 y el 21\%, respectivamente. En cambio, se estima que la supervivencia con metástasis a distancia es del $51 \%$ a 1 año, del $26 \%$ a los 5 años y del $10 \%$ a los 10 años. Los factores de mal pronóstico incluyen el estadio de la enfermedad y la edad avanzada en el momento del diagnóstico. En modelos de análisis multivariado sólo son indicadores significativos e independientes de supervivencia el estadio y la edad del paciente en el momento del tratamiento inicial ${ }^{13}$.

\section{CONCLUSIÓN}

Se concluye que el CMT metastásico responde mal a la radioterapia y la quimioterapia, por lo que es imprescindible la realización de un adecuado screening en personas en riesgo y la posibilidad de una cirugía temprana. Al respecto se podría proponer la medición de CT plasmática a todos los pacientes con enfermedad nodular de tiroides. Es importante realizar en todos los casos de CMT el estudio genético y descartar enfermedades asociadas. El único tratamiento curativo en el CMT es la cirugía en forma precoz y completa, para lo que se requiere un diagnóstico temprano; además, es una opción la implementación de un enfoque quirúrgico agresivo, ya que el CMT se asocia a una alta tasa de enfermedad persistente y recidiva. No debemos olvidar que existen nuevos fármacos en investigación basados en la oncología molecular como potencial tratamiento para pacientes con CMT en estadios avanzados.

\section{CONFLICTO DE INTERESES}

Los autores declaran no tener ningún conflicto de intereses.

\section{FINANCIAMIENTO}

Los autores no han recibido ningún tipo de financiamiento para la elaboración de este artículo.

\section{REFERENCES}

1. Guía de Práctica Clínica. Diagnóstico y Tratamiento del Nódulo Tiroideo. Evidencias y recomendaciones. Consejo de Salubridad General. CENETEC. México, Secretaria de Salud. 2009.
2. Lanzarini SE, Marambio GA, Rodríguez MF, et al. Carcinoma Medular de Tiroides: Experiencia de 20 años. Rev. Chilena de Cirugía. 2010;62:15-21.

3. Longobardi V. Guía de Práctica Clínica. Carcinoma Medular de Tiroides. Año 2011. Pp 1-12.

4. Forga Llenas L. Genética del carcinoma medular de tiroides. Endocrinol Nutr. 2007;54:371-81.

5. Hundahl SA, Fleming ID, Fremgen AM, Menck HR. A National Cancer Data Base Report on 53,856 cases of Thyroid Carcinoma Treated in the U.S. 1985-1995. Cancer. 1998;83:2638-48.

6. Wells SA, Franz C. Medullary carcinoma of the thyroid gland. World d Surg. 2000;24:952-6.

7. Bugalho MJ, Domingues R, Rosa Santos J, Catarino AL, Sobrinho L. Mutation analysis of the RET protooncogen and early thyroidectomy: results of a Portuguese cancer centre. Surgery. 2007;141:90-5.

8. Dottorini ME, Assi A, Sironi M, Sangalli G, Spreafico G, Colombo L. Multivariate analysis of patients with medullary thyroid carcinoma. Prognostic significance and impact on treatment of clinical and pathologic variables. Cancer. 1996;77:1556-65.

9. Moley JF, DeBenedetti MK. Patterns of nodal metastases in palpable medullary thyroid carcinoma. Recommendations for extent of node dissection. Ann Surg. 1999;229:880-8.

10. Scollo C, Baudin E, Travagli JP, et al. Rationale for central and bilateral lymph node dissection in sporadic and hereditary medullary thyroid cancer. J Clin Endocrinol Metab. 2003;88:2070-5.

11. Fleming JB, Lee JE, Bouvet $M$, et al. Surgical strategy for the treat ment of medullary thyroid carcinoma. Ann Surg. 1999;230:697-707.

12. Moley JF, DeBenedetti MK, Dilley WG, Tisell LE, Wells SA. Surgical management of patients with persistent or recurrent medullary thyroid cancer. J Intern Med. 1998;243:521-6.

13. Guía Básica del Cáncer Tiroideo. ThyCa: Thyroid Cancer Survivor's Association Inc. 2013. Pp 8,9. Available at: www.thyca.org

14. Brandi ML, Gagel RF, Angeli A, et al. Guidelines for diagnosis and therapy of MEN type 1 and type 2. J Clin Endocrinol Metab. 2001;86:5658-71.

15. Eng C, Clayton D, Schuffenecker I, et al. The relationship between specific RET proto-oncogene mutations and disease phenotype in multiple endocrine neoplasia type 2. International RET Mutation Consor tium Analysis.

16. Yu LS, Chen L. Mandible metastasis as the initial manifestation of breast carcinoma -report of a case. Chin Dent J. 1991;1098-103.

17. JAMA. 1996; 276:1575-9. Shamin A, Bhargava Khan N, Ahmad Z, Afrez N. Metastatic mandibular adenocarcinoma. J IACM. 2007;8:196-8.

18. Alvarez AC, Iglesias RB, Pazo IS, Delgado SG. Colon adenocarcinoma with metastasis to the gingiva. Med Oral Patol Oral Cir Bucal. 2006;11:E85-7.

19. Sanchez JJ, Acebal BF, Arevalo ARE, Molina MM. Metastatic tumours in upper maxillary bone of esophageal Adenocarcinoma. A case report. Med Oral Patol Oral Cir Bucal. 2005;10:252-7.

20. Anthony WT, Agargwal N, Joseph PG. Oral cavity metastasis of renal cell carcinoma: A case report. J Med Case Reports. 2008;2:313.

21. Halachmi S. Madeb R, Madjar S, Wald M, River Y, Nativ O. Numb chin syndrome as the presenting symptom of metastatic prostate carcinoma. Urology. 2000;55:286.

22. Medrano OZME, Rodriguez-Cuevas SA, Labastida AS, Gomez AF. Cáncer medular de tiroides. Oncología (Rev Mex Oncol) 1992;7:20-3 